\section{Pogonophora in the Hardangerfjord, Western Norway}

UNTIL recently, Pogonophora were known only from the north-western Pacific and from Indonesia. All species being found in the deep sea such a limited distribution seemed unlikely, the more so as the tubes of the animals are hair-like and easily overlooked. In fact, new investigations and revision of old collections have proved that the Pogonophora are widely distributed and also occur in relatively shallow water. Thus one species is now known from the Polar Sea, and Kirkegaard found Pogonophora in the Galathea collections from Indonesia ${ }^{1}$ and from the Gulf of Panama ${ }^{2}$. Jägersten ${ }^{3}$ described Siboglinum ekmani from old collections from about $500 \mathrm{~m}$. in the Skagerrak, and he also described the larva of another species from only $180 \mathrm{~m}$. depth in the same area ${ }^{4}$. Kirkegaard ${ }^{5}$ re-investigated the deepest parts of the Skagerrak and found more material of $S$. ekmani, and Southward ${ }^{6-8}$ has obtained several species from the continental slope south-west of England and west of Ireland.

As the fauna of the Norwegian Deep in the Skagerrak comprises many typical deep-sea animals which also live in the deep Norwegian fjords, Pogonophora could be suspected to occur in our rich collections from the Hardangerfjord. Several samples of undetermined narrow tubes were re-investigated. Between them were found many still more slender, red-brown tubes up to $17.5 \mathrm{~cm}$. Iong and strongly resembling those of Siboglinum ekmani. New dredgings in different parts of the Hardangerfjord have proved this species to be fairly abundant in depths between 396 and $840 \mathrm{~m}$.

The material has been sent to Prof. G. Jägersten, who has confirmed that part of it is very similar to $S$. ekmani, whereas one animal probably belongs to another species. Thus at least two species of Pogonophora seem to occur in the Hardangerfjord.

Biological Station,

Espegrend, Norway.

March 6.

${ }^{1}$ Kirkegaard, J. B., Galathea Report, 2, 79 (1956).

2 Kirkegaard, J. B, Galathea Report, 2, 183 (1958).

3 Jagersten, G., Zoologiska Bidrag fran Uppsala, 31, 211 (1956).

- Jägersten, G., Zoologiska Bidrag fran Uppsala, 32, 67 (1957).

s Kirkegaard, J. B., Nature, 181, 1086 (1958).

${ }^{6}$ Southward, A. J., and Southward, E. C., Nature, 181, 1607 (1958)

'Southward, A. J., Nature, 182, 272 (1958).

s Southward, E. C., and Southward, A. J., J. Mar. Biol. Assoc. U.K., 37. $627(1958)$.

\section{Utilization of Nutritive Spheres in the Proteus Group of Amoebae}

IN all members of the proteus group of Amoebae there occur spherules of a pale blue colour to which the name 'excretion spheres' was given by early writers. This designation was changed to "nutritive spheres" by Hayes" in 1924. The reaction of these bodies to various reagents has been described in an appendix by Hayes to Taylor's paper entitled "A. proteus, some New Observations on its Nucleus Life History and Culture", and further information about them was later published by Taylor ${ }^{3}$.

The diameter of these bodies is proportional to the age of the Amoeba. A quick examination of the nutritive spheres enables the observer to distinguish a newly metamorphosed Amoeba from an adolescent, mature or senile creature. It is necessary here to emphasize the importance to the reader of stating the age of the Amoeba when describing its reactions, behaviour, etc. Reaction to a certain stimulus characteristic of mature Amoebae may be very different from that of an adolescent. To repeat: the diameter of the nutritive spheres is a criterion of the age of the Amoeba, which should always be given.

In my paper ${ }^{2}$ I used a hæmatoxylin which stained the nutritive spheres purple. In this account it was shown that during the differentiation of the spores in the adult Amoeba the nutritive spheres were gradually used up, so that those Amoebae which were full of spores could be picked out by the extreme scarcity of coloured nutritive spheres, the degree to which sporulation had proceeded being indicated by the number of nutritive spheres present.

In sections through sporulating Amoebae, nutritive spheres which had begun to yield up their contents looked like collapsing balls, every stage from a fully inflated to a completely collapsed sphere being found.

Recently, I have seen this phenomenon in living material. Under natural conditions the proteus group $^{1}$ are mature and senile in the winter months. If these mature specimens, easily identified by their large nutritive spheres $(7 \mu)$, be placed in a Petri dish and kept under observation, the gradual loss of contents of the nutritive spheres, as sporulation proceeds, can be witnessed; deformed spheres of every kind, that is to say, spheres having given up varying volumes of their contents, can be picked out.

Convent of Notre Dame, Monica TAylor

Glasgow, W.2.

Feb. 11.

'Jepps, M. W., "The Protozoa, Sarcodina" (Oliver and Boyd, Edinburgh, 1956)

${ }^{2}$ Taylor, M., Quart. J. Micr. Sci., Appendix, 69 (1924).

${ }^{3}$ Taylor, M., Nature, 143, 685 (1939).

\section{Second Flowering in Oryza sativa (var. indica)}

Is India rice is normally harvested when ripe by cutting off the leaves and stems near ground-level. Shortly before this operation the field is allowed to dry. There is very little regeneration, though it is well known that rice can be propagated vegetatively by 'ratooning'. In 1958 three small plots of $5 \cdot 2$ square metres each at Giridih in Bihar were planted with the aus (rapidly maturing) variety $\mathrm{CH}-10$ in July. Owing to the late monsoon the crop was poor. Instead of drying and cutting as usual, the plots were not allowed to dry, and the ears were plucked by hand on October 10. The plots produced a second erop which was harvested on November 23 by the usual method. Table 1 shows the yield of paddy for two harvests of the three plots.

The total yield was thus increased by 117 per cent, that is to say, more than doubled. The second crop was harvested at the same time as the aman (slowly maturing) rice in the neighbouring plots. Table 1. YIELD OF PADDY (DRY WHIGHT, GM.) FOR THREE PLOTS
EACH $5 \cdot 2$ SQUARE METRES IN AREA FOR THE FIRT AND THE SECOND EACH 5.2 SQUARE METRES IN AREA FOR THE FIRST AND THE SECOND

\begin{tabular}{|l|c|c|c|c|}
\hline & \multicolumn{3}{c|}{ CRoP } \\
\hline Yield & & & & \\
\hline $\begin{array}{l}\text { First crop } \\
\text { Second crop }\end{array}$ & 1 & 2 & 3 & Total \\
\hline
\end{tabular}

